\title{
Knowledge Hiding as an Unprecedented Auxiliary in the Knowledge Management Process for Protection and to Achieve Innovation: The Case of a Pharmaceutical MNE Operating in Egypt
}

\author{
Said Shabban Abdo* \\ Associate Professor: School of Management, Modern University for Technology \& Information (MTI); El-hadaba El-Wosta, Mokatam, \\ Cairo, Egypt. \\ Email: Said.sayed@mgt.mti.edu.eg (*Corresponding Author) \\ David Edgar \\ Professor of Strategy and Business Transformation, Department of Management and HR Management, Glasgow School for Business and \\ Society, Glasgow Caledonian University, Glasgow, Scotland. \\ Email: D.A.Edgar@gcu.ac.uk
}

Received: 27 May 2021; Revised: 29 June 202 1; Accepted: 23 July 2021; Published: 31 August 2021

\begin{abstract}
This paper investigates the process and strategies used by a pharmaceutical MNE in Egypt to acquire, assimilate, transform, apply and protect its knowledge for the purpose of achieving innovation. The analysis is conducted through the lens of absorptive capacity theory and based on seven interviews with key stakeholders to explore how knowledge protection practices and supporting mechanisms were applied to achieve innovation and organizational effectiveness., Thematic analysis reveals that Knowledge infrastructure capabilities constitute the backbone of knowledge processing capabilities, supported by other constituents such as appropriability regime mechanisms, the role of management (HRM), knowledge management approach, knowledge hiding, and the absorptive capacity. The study concludes that successful knowledge management is a byproduct of integrating knowledge infrastructure capability with processing capabilities, and mediated by knowledge hiding mechanisms and strategies. The findings offer a valuable empirical perspective from a pharmaceutical MNE operating in Egypt and provide new insights into the nature of the intermediating influences of knowledge management processes that lead to innovation and superior organizational performance.
\end{abstract}

Keywords: Absorptive capacity, Organizational effectiveness, Knowledge hiding, Appropriability regime, Knowledge protection, Knowledge management.

\section{Introduction}

Knowledge is a pivotal valuable strategic asset for organizational survival (Barão, de Vasconcelos, Rocha, \& Pereira, 2017) and competitive advantage (Barley, Treem, \& Kuhn, 2018) making knowledge management $(\mathrm{KM})$ essential to survival in contemporary business environments (Venkitachalam \& Willmott, 2015). The ability to acquire/create, share and apply knowledge supports firms in transforming it into commercial ends, and is a vital competency for today's organizations. Khamseh and Jolly (2008) argue that one of the pillars of knowledge management is absorptive capacity, defined by Zahra and George (2002) as a bundle of organizational practices and routines which allow knowledge to be acquired, assimilated, transformed and exploited. Such processes are mutually dependent and are seen as essential in an organizational process (Todorova \& Durisin, 2007).

Consequently, valuable knowledge performs a significant role in building and sustaining the organization's competitive advantage. However, there are often frequent knowledge leakages or loss, 
owing to increased workforce turnover, human errors, facts being implied from knowledge made available through several sources, or poor information management strategies, security and practices (Ahmad, Bosua, \& Scheepers, 2014). Such knowledge leakage (defined by Annansingh (2005) as the deliberate or accidental loss of knowledge to unauthorized personnel within or outside an organizational boundary) is significant as it can result in reputational damage, loss of returns and reduce organizational productivity (Ahmad et al., 2014). It therefore constitutes a significant challenge for management with knowledge requiring protection (Hernandez, Sanders, \& Tuschke, 2015) and the development of effective knowledge management processes (Davenport \& Prusak, 1998).

Such processes can be viewed as a "structured coordination to manage knowledge effectively" (Gold, Malhotra, \& Segars, 2001) and include not only the creation, acquisition, conversion and application of knowledge, but also the protection of the resulting and existing knowledge itself (Lee, Kim, \& Kim, 2012). Despite knowledge being deemed an essential organizational asset and empirical evidence recognizing that successful knowledge protection can considerably enrich organizational output (Lee, Chang, Liu, \& Yang, 2007) it has been found that "knowledge managers still seem to pay little attention to security issues in their jobs, and knowledge protection research is still in its infancy" (Manhart \& Thalmann, 2015). Consequently, fears regarding secrecy of organizations' information and customers' knowledge often draw managerial consideration to protecting an organization's own knowledge and information assets (Ahmad et al., 2014) often through legal mechanisms rather than culture and practice. Yet, there is empirical evidence beyond the legalistic protectionism, ratifying the correlation between absorptive capacity and intellectual capital (protection of knowledge) as a trigger of organizational innovation (Cassol, Gonçalo, \& Ruas, 2016) and therefore a consideration for cultural perspectives on knowledge protection.

Given the former, it is not unreasonable to conclude that absorptive capacity theory can act as a lens to view the knowledge management process and in doing so, discover what mediates the link between the knowledge management process and superior organizational performance. As such, we use absorptive capacity theory in this study to investigate the process and strategies used, by a pharmaceutical MNE operating in Egypt, to acquire, assimilate, transform, protect, and apply its knowledge to facilitate innovation.

\section{Literature Review and Framework}

As knowledge is considered an important source of competitive advantage, organizations need to protect it through both the knowledge infrastructure capability and knowledge process capability (Manhart \& Thalmann, 2015). This section discusses the different processes involved in knowledge management and their benefits before presenting the research questions formulated as a result of this review.

\subsection{Knowledge Management Processes}

Knowledge management capabilities relate to the knowledge management processes in an organization that improve and utilize knowledge (Chiu \& Chen, 2016). Such processes have been defined as "an ongoing set of practices embedded in the social and physical structure of the organization with knowledge as their final product" (Pentland, 1995). Grounded on earlier studies, Gold et al. (2001) identified four key processing capabilities of knowledge management that are indispensable for effective knowledge flow. These capabilities are acquisition, conversion, application and protection, and can be implemented via practicing routines (absorptive capacity) to establish capabilities and ways to measure them Gold et al. (2001). In particular, "KM [knowledge management] process capability is essential to enable the organization to capture, reconcile, and transfer knowledge in an efficient manner" (Gold et al., 2001). The four knowledge processes have been found to be strongly connected to organizational performance (Mills \& Smith, 2011) and are therefore significant for competitive survival. 


\subsubsection{Knowledge Acquisition Process}

The knowledge acquisition process is intended to enable the accumulation of knowledge that resides within the firm or outside it Gold et al. (2001). "Knowledge is accumulated when units within the organization as a whole gain new understanding" (Chakravarthy, McEvily, Doz, \& Rau, 2005). These processes focus on benchmarking and collaboration. Benchmarking involves a firm identifying best practices from organizations, including itself, and evaluating the existing state of a specific process to identify gaps and opportunities (Marti, 2000). Collaboration might occur between individuals and between the organization and its network of business associates such as joint venture partners or alliances, which together are potential sources of knowledge. Accumulation of knowledge also acquires knowledge that is created through experimentation (Nonaka \& Takeuchi, 1995). Thus, the knowledge acquisition process depends on the absorptive capacity of organization to recognize, understand and capture knowledge from a variety of sources (Cohen \& Levinthal, 1990) because all the necessary innovation skills may not be found in a single organization (Gold et al., 2001). As a result, organizations have to take advantage of their acquisition capabilities to enhance product innovation, patent practices and protect their knowledge. As such there is a close link that needs to be explored between the acquisition and accumulation of knowledge, knowledge protection and the absorptive capacity of organization as a whole unit.

\subsubsection{Knowledge Conversion Processes}

This phase of the KM process is focuses on making current knowledge useful by enabling organizations to organize, represent, integrate, combine, structure, coordinate, or distribute knowledge. Integrating knowledge from different sources improves efficiency by removing the extra volume (Gold et al., 2001). The conversion processes allow firms to replace existing knowledge with the most updated knowledge. The most cited mechanisms in the literature for facilitating conversion and integration of knowledge are group problem solving and decision making, rules and directives, routines and sequencing. Moreover, the ability of individuals to convert existing knowledge to be shared and distributed has been found to have a positive relationship with organizational performance, when moderated by absorptive capacity (Nodari, Oliveira, \& Maçada, 2016).

The process of knowledge conversion constitutes a series of activities which produce competitive advantage. These comprise the organizational capabilities to acquire, assimilate, transform and exploit knowledge, known as the absorptive capacity components (Zahra \& George, 2002). This close link between knowledge conversion and the absorptive capacity of organization calls for further investigation that needs to be explored.

\subsubsection{Knowledge Application Process}

The knowledge application process refers to the utilization of the converted knowledge (Wu \& Chen, 2014) including how it is shared stored and retrieved, as well as its contribution and application (Gold et al., 2001). The application process involves looking critically at their own activities and outcomes, to ratify either whether the acquisition and conversion of knowledge were successful (Pandey, Dutta, \& Nayak, 2018). According to Grant (1996) the chief source of competitiveness lies in the capability to apply knowledge to improve efficiency and reduce cost, rather than its capability to create new knowledge per se. This process is linked to the absorptive capacity to apply new assimilated and or transformed knowledge into activities, products or services, to boost innovation, flexibility and performance (Todorova \& Durisin, 2007). Absorptive capacity allows the organization to play a prominent role in giving valuable ideas and feedback to its external allies and discovering innovative means of applying their knowledge (Arias-Pérez, Lozada, \& Henao-García, 2020). This highlights the close link between knowledge application and the absorptive capacity of an organization, which requires further exploration.

Journal of Contemporary Research in Business, Economics and Finance
ISSN: 2641-0265
Vol. 3, No. 3, pp. 109-127, 2021
DOI: $10.33094 / 26410265.2021 .33 .109 .127$
C) 2021 by the authors; licensee Learning Gate




\subsubsection{Knowledge Protection Process}

Knowledge as an asset is the source of competitive advantage once it is recognized by gatekeepers (knowledge experts) as rare and inimitable (Barney, 1991). Consequently, protection processes are very important for an organization. Knowledge protection processes are those "designed to protect the knowledge within an organization from illegal or inappropriate use and theft" (Gold et al., 2001). Protection involves actions that attempt to preserve the proprietary nature of an organization's knowledge assets, which comprise pursuing legal protection, developing educating policies to curtail turnover, and educating employees regarding the forms of knowledge they must not share with their subordinates or seniors in other organizations (Appleyard, 1996).

It has been argued that influences such as previous experiences, appropriability regimes, and social integration mechanisms may present as moderators of absorptive capacity and innovative interactions (Mikhailov \& Reichert, 2019). The appropriability regime refers to the protection of the unique advantages acquired and the profits that originate from the protected knowledge (Cappellari, Welter, Hermes, \& Sausen, 2019).

According to Hurmelinna-Laukkanen (2012) that there are many appropriability influences and mechanisms such as patents, protection of utility models and designs, trade secret protection, copyrights, trademark protection, or even being the first mover. He argues that organizations that feel protected will be more inclined to share their knowledge and possess the capacity to nurture absorptive capacity. A robust regime of appropriability is essential to protect organization's knowledge resources and exploit its absorptive capacity through innovations, owing to the high costs of potential imitation by rivals (Zahra \& George, 2002). As such, there is a close link between knowledge protection and the absorptive capacity of organization, which needs to be explored.

\subsection{The Importance of Knowledge Protection for Organizations Identified in the Literature}

There are many benefits for the protection of knowledge in organizations identified in the literature. For instance, the prevention of undesired knowledge spillovers where knowledge is leaked to extrinsic individuals (Ahmad et al., 2014) the decrease of visibility of knowledge to externals (Lee et al., 2007) and the inhibition of damage to the organization s which might come from leaks by individuals who have been made redundant and are inaccessible, and those who are retired or have left the organization (Jennex \& Durcikova, 2013).

However, Manhart and Thalmann (2015) argue that while knowledge protection performs an indispensable role in maintaining an organization's competitive advantage, knowledge management scholars have up to now been inclined to focus on the facilitation of knowledge sharing rather than on knowledge protection, which is often a neglected or underdeveloped area. (They point out that overlooking knowledge protection may lead to the duplication of ideas by extrinsic organizations and then impede the utilization of innovations. Consequently, these authors, call for more profound empirical investigations, robust consideration of theories in knowledge protection research, and research on how organizations can construct a strategy of knowledge protection (Manhart \& Thalmann, 2015).

Furthermore, a comprehensive analysis of the knowledge management literature found little emphasis on the importance of knowledge protection (Pandey et al., 2018). Although it has been argued (that the four processes identified by Gold et al. (2001) as shown in Figure 1. are "sufficiently broad to permit complete analysis of organizational knowledge management capabilities" (Lin, 2007) it appears that knowledge processing capability alone cannot guarantee a successful initiative of knowledge management.

Although these processes are a must to create, acquire, transform and apply knowledge (Pandey et al., 2018) they need to be interplayed with the four components of absorptive capacity: acquisition, assimilation, transformation and exploitation. Acquisition refers the firm's ability to identify and evaluate external and internal knowledge. Assimilation refers the habits, routines, and process that the firm uses to assess and understand the captured knowledge, which is grounded on individuals' 
understanding and interpretation and making sense of this knowledge, Transformation refers the firm's ability to improve and refine the habits that facilitate merging prior knowledge and the newly acquired and assimilated knowledge; organizations can add or delete knowledge through this filtration and refining process, (Albort-Morant, Henseler, Cepeda-Carrión, \& Leal-Rodríguez, 2018). Exploitation refers to the application of new external knowledge for commercial ends, as shown in Figure 2. Thus, absorptive capacity is deemed a prerequisite for practices that comprise the thoughtful management of the flows of knowledge outside the organizational bounds, aiming to generate innovations (Arias-Pérez et al., 2020).

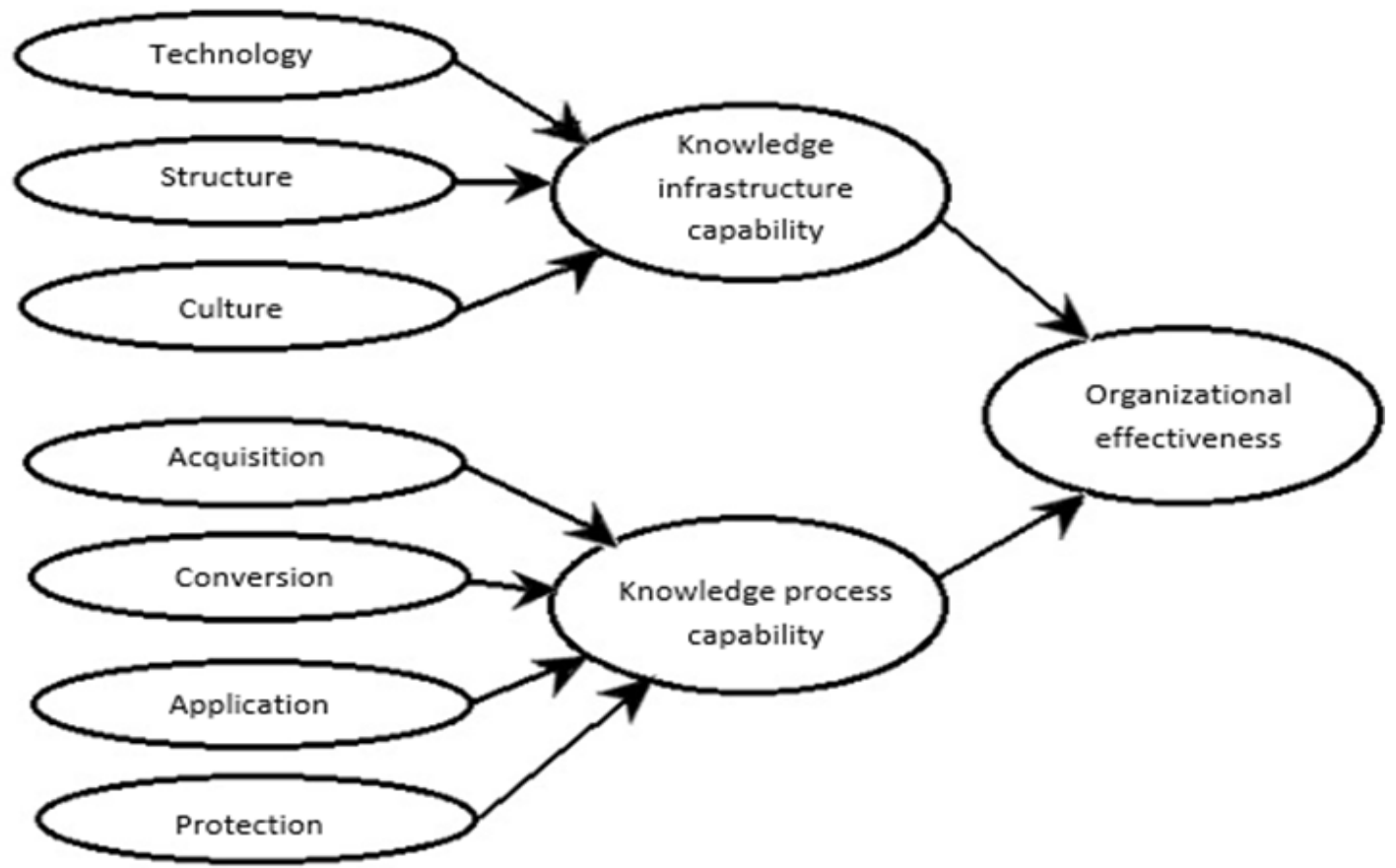

Figure-1.

Knowledge management capabilities and organizational effectiveness (Gold et al., 2001).

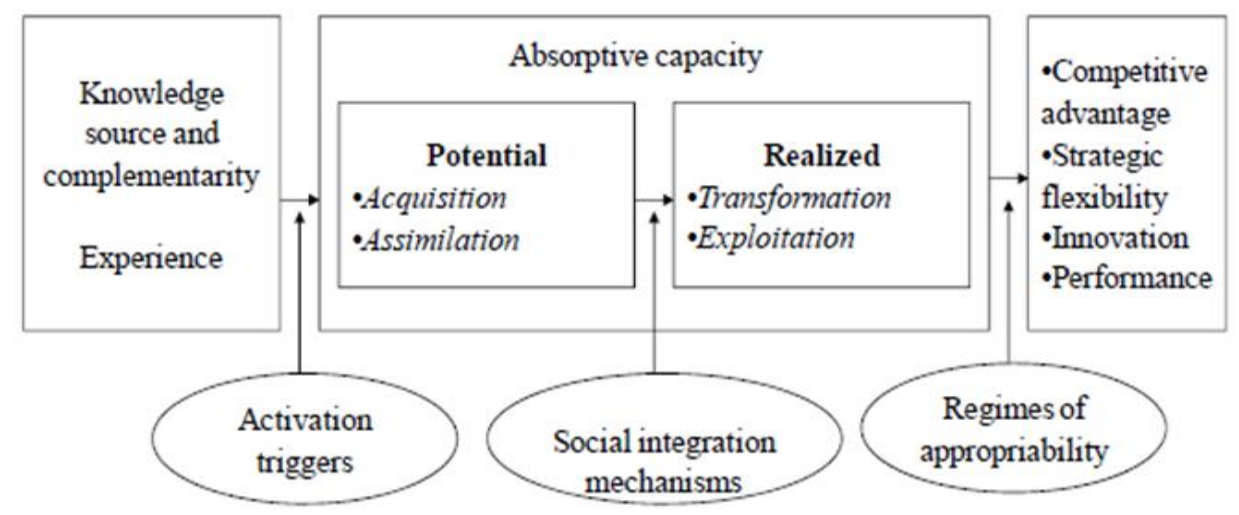

Figure-2.

The model by Zahra and George (2002).

Moreover, it has been claimed that most of the researched publications are not practical and do not study knowledge protection from the perspective of a particular theory (Manhart \& Thalmann, 2015). 
Therefore, the aim of the current research is to investigate the process and strategies that a particular firm, in this case a pharmaceutical MNE, uses to acquire, assimilate, transform, apply and protect its knowledge to achieve innovation, through the lens of absorptive capacity theory as a supportive mechanism for the knowledge management process to achieve competitive advantage. In order to address the above aim, the following questions have to be answered:

\subsection{Research Questions}

1. How can the pharmaceutical MNE protect their knowledge effectively, and what are the challenges that managers face in protecting knowledge?

2. Why does knowledge leak and how can it be protected, and what are the key mechanisms/ strategies exist to protect knowledge?

3. To what extent can absorptive capacity theory act as a supportive mechanism in the relationship between the knowledge management process and organizational performance?

4. What are the structures of knowledge acquisition from external and internal environments, together with the mechanisms of information distribution and utilization for achieving competitive advantage?

\section{Methodology}

\subsection{Research Method and Design}

This research was conducted by employing qualitative inquiry through the lens of absorptive capacity theory in interpretive paradigms, so as to better understand the process and strategies used by the pharmaceutical MNE to protect its knowledge for achieving innovation.

\subsection{Sample Eं Participants}

Seven senior managers (SMs) of a multinational pharmaceutical MNE in Egypt were interviewed (Table 1). Five interviewees were male, and one was female; each interview lasted between forty and fifty minutes. The researcher refrained from recruiting other participants once the results had reached theoretical saturation, where the additional participants did not produce extra or dissimilar information or experiences. To ratify that the study was meaningful, a comprehensive interpretation of the participants' experiences was provided (Smith, Larkin, \& Flowers, 2009).

\subsection{Data Collection Instruments}

Semi-structured face-to-face interviews were conducted in the participants' offices, where convenient for participants, and all the informants permitted the interview to be recorded and transcribed. The procedure was pre-planned, with open-ended questions that permitted the applicants to provide an individual viewpoint while keeping the researcher concentrated on the subject being investigated (Leech, 2002). Respondents provided some contextual information regarding their job responsibilities and organizational characteristics, and were then requested to describe strategies and mechanisms they had applied to protect knowledge, and events where these aided them to achieve innovation.

\subsection{Data Analysis}

The research used qualitative inquiry and especially thematic analysis, which permits the analysis of a great deal of data from many applicants to be investigated and synthesized into a meaningful interpretation (Boyatzis, 1998). An inductive thematic analysis methodology was applied to discover important experience gained from semi-structured interviews linked to the participant's experiences (Braun \& Clarke, 2006). Since the data and sample size were manageable, coding was performed manually rather than using auto coding, following Basit (2003) and Lewins and Silver (2007). In a comparison of personal experiences between manual and electronic coding Basit (2003) concluded that "the choice will be dependent on the size of the project, the funds and time available, and the inclination 
and expertise of the researcher" (p. 143) Thus researchers should not feel "compelled to make use of auto coding just because it is available".

Table-1.

The Seven Interviews with SMs of a multinational MNE in Cairo, Egypt.

\begin{tabular}{|c|c|c|c|c|c|}
\hline No. & Gender & $\begin{array}{l}\text { Job } \\
\text { Title }\end{array}$ & $\begin{array}{l}\text { Interview } \\
\text { Duration }\end{array}$ & Profile & Additional Skills \\
\hline 1 & Male & $\begin{array}{l}\text { Senior } \\
\text { Manager }\end{array}$ & 45 & $\begin{array}{l}25 \text { years of experience } \\
\text { in pharmaceutical } \\
\text { industry }\end{array}$ & $\begin{array}{l}\text { R\&D Group Leader, evaluate } \\
\text { and design research material }\end{array}$ \\
\hline 2 & Male & $\begin{array}{l}\text { Senior } \\
\text { Manager }\end{array}$ & 40 & $\begin{array}{l}30 \text { years of experience } \\
\text { in pharmaceutical } \\
\text { industry }\end{array}$ & $\begin{array}{l}\text { Director of HR, Rewards and } \\
\text { operations }\end{array}$ \\
\hline 3 & Male & $\begin{array}{l}\text { Senior } \\
\text { Manager }\end{array}$ & 41 & $\begin{array}{l}28 \text { years of experience } \\
\text { in pharmaceutical } \\
\text { industry }\end{array}$ & $\begin{array}{l}\text { IT and security managers, } \\
\text { network director }\end{array}$ \\
\hline 4 & Male & $\begin{array}{l}\text { Senior } \\
\text { Manager }\end{array}$ & 44 & $\begin{array}{l}25 \text { years of experience } \\
\text { in pharmaceutical } \\
\text { industry }\end{array}$ & $\begin{array}{l}\text { Training \& Development, } \\
\text { senior supervisor }\end{array}$ \\
\hline 5 & Female & $\begin{array}{l}\text { Senior } \\
\text { Manager }\end{array}$ & 47 & $\begin{array}{l}12 \text { years of experience } \\
\text { in pharmaceutical } \\
\text { industry }\end{array}$ & $\begin{array}{l}\text { Managing Compliance } \quad \& \\
\text { internal control }\end{array}$ \\
\hline 6 & Male & $\begin{array}{l}\text { Senior } \\
\text { Manager }\end{array}$ & 47 & $\begin{array}{l}10 \text { years of experience } \\
\text { in pharmaceutical } \\
\text { industry }\end{array}$ & $\begin{array}{l}\text { Managing Compliance \& legal } \\
\text { affairs }\end{array}$ \\
\hline 7 & Male & $\begin{array}{l}\text { Senior } \\
\text { Manager }\end{array}$ & 46 & $\begin{array}{l}17 \text { years of experience } \\
\text { in pharmaceutical } \\
\text { industry }\end{array}$ & $\begin{array}{l}\text { Production } \\
\text { inventory manager / Member of } \\
\text { higher research committee in } \\
\text { medicine production }\end{array}$ \\
\hline
\end{tabular}

\section{Findings and Discussion}

The process and strategies that the pharmaceutical MNE uses to acquire, assimilate, transform, apply and protect its knowledge for achieving innovation through the lens of the absorptive capacity theory as supportive mechanism for the knowledge management process for achieving competitive advantage have been investigated and semi-structured interviews have been conducted to reveal that, while many authors like Gold et al. (2001) have divided knowledge management mechanisms into knowledge infrastructure capability, and knowledge process capability which can lead to organizational effectiveness, the authors did not present an empirical evidence to illustrate the effect of the former on the latter for achieving organizational effectiveness as the for the current research does.

\subsection{Technological Infrastructure Capability Supports Protection of Acquired Knowledge for Innovations}

The technological infrastructure capability denotes the technology-enabled connections of a business. Knowledge management is an area of information technology practice that developed from the disciplines of computer science (Townley, 2003) and information systems are now indispensable for storing explicit knowledge and saving information (Davenport \& Prusak, 1998). Technological infrastructure capabilities have been implemented as the as the combined gateway of the organization (Holsapple \& Joshi, 2001) that supports the knowledge acquisition phase by overcoming communication obstacles, and thus enables organizations to acquire, gather, combine, and retrieve knowledge from a broad spectrum outside its peripheries. In addition, knowledge management has been defined as one of the firm's capabilities (Gold et al., 2001) where through its technological component, the firm can 
obtain, transform and apply new external and internal knowledge to its commercial ends; this is the meaning of absorptive capacity.

In line with the perceptions in the literature, the SMs of the pharmaceutical MNE interviewed in this study emphasised the role of the technological component in infrastructure capability in supporting knowledge protection and acquisition process for innovations in their company.

"Our acquired information stored and distributed by the SAP computer system, as it is very secure with authority level, and those who want to access outsourcing of externals of our company through the DPN system which is very secure and safe this allow us to acquire, select and reciprocate information with suppliers, counterparts, rivals and our headquarters in the United States. which is so secure and safe that cannot be hacked by net pirates" (Respondent 1).

"We have a very restricted IT system for protecting our knowledge, we have to change our passwords to log in the system every 45 days, we have refreezing system in our PCs, we share our knowledge with its relevant expertise not with the common, we do not use WhatsApp messages, Facebook, etc. We use our internal SAP system carefully and thoroughly, so as to prevent knowledge and information leaks" (Respondent 2).

"We have our internal secure application called "Amoun application" with certain password and login process so as to transfer and protect our knowledge safely; it cannot be hacked or penetrated by network pirates to protect our inventions and innovations"( Respondent 4).

In the above excerpts, the interviewees described how they acquire knowledge from their suppliers, counterparts, rivals, collaborators and headquarters and protect this knowledge in technological software applications and systems to support their dominance and innovations, This supports the views in the literature regarding the importance of knowledge being acquired by employees from other firms and collaboration between the firm and its business partners and its network to allow innovation (Gold et al., 2001; Inkpen \& Beamish, 1997). In addition, they described the information technology practices they used to support the process of knowledge acquisition for superior organizational performance, in agreement with Alavi and Leidner (2001). As well as the technology in their infrastructure capability that provides the means and tools to protect knowledge effectively for proper utilization and innovation.

The interviewees emphasized the role of knowledge protection by codification in technological means for protection directly following their acquisition of knowledge for maximizing their absorptive capacity and allow innovation, this also accentuate the relationship between knowledge acquisition, protection, and innovation, this also in concurrence with Boisot (1999) view that value-creation through acquired knowledge can only be understood via knowledge acquisition that comprises both knowledge personalization and codification strategies. Furthermore, the current research not only corroborates the work of other scholars by hypothesizing and empirically confirming that there is a strong relationship among absorptive capacity, knowledge acquisition, and innovation (Hurmelinna-Laukkanen, 2012; Todorova \& Durisin, 2007) but also contributes to the literature by exploring that knowledge protection as a catalyst among the these three elements for innovations in the context of pharmaceutical MNE operating in Egypt as argued above.

\subsection{Structural Capability Supports Protection of Converted Knowledge for Innovations}

Researchers have underscored that infrastructure capabilities constitute a significant role in the failure or success of an organization's knowledge management initiative. It denotes to the degree to which the organization is structured to stimulate knowledge-related activities (Pandey \& Dutta, 2013).

Structure in organizations denotes the formal operation and knowledge structure, in addition to the existence of rules and trust mechanisms (Gold et al., 2001). According to Ruggles (1998) structures can inspire creativity and agility, which constitute an effective KM structure. The third phase of absorptive capacity is the transformation that refers to the ability to combine previous knowledge with newly acquired and integrated knowledge (Arias-Pérez et al., 2020). The conversion process comprises the basic input (data, information, knowledge) and output (intellectual capital) of the knowledgetransformation process (Pandey et al., 2018). Thus, the structural capability supports the 
complementary relationship between knowledge conversion and protection for innovation through the knowledge transformation phase of the absorptive capacity, as described by one of the interviewees.

"I have three managers for protecting our staff and knowledge, namely manager of employee's safety, manager of physical place safety, and senior manager of information security, who is responsible for the security of our knowledge - even a gossip or hear-saying - as it might hurt our business. For instance they might come up with some untrue news regarding the selling of our company to an external investor. Then we will face chaos that will harm our production, name and market share and lose our innovative REDD." (Respondent 3).

In this quote, the SM emphasised that the allocation of tasks, rules and responsibilities enabled the firm to control and their knowledge assets and outcomes of R\&D and protect them from any inaccurate and false information that might hurt their shares in the stock markets and endeavors for innovation. This confirms the views of Gold et al. (2001) that knowledge management hinges essentially on organizational structure: that is, formal distribution of tasks, activities, responsibilities, and specialists within an organization, and structure, such as the allocation of duties and procedures that lead to successful knowledge management (Abualoush, Masa'deh, Bataineh, \& Alrowwad, 2018).

The interviewees also explained how their systemic structure of rewards and incentives promotes loyalty among their employees, which turn promotes knowledge protection behavior which benefits not only the individuals but the whole company.

"We are investing in individuals, by providing them with care, pension schemes, bonuses, promotions, motivations, rewards so as to promote loyalty and trust to make our staff by that protecting our knowledge for their long-lasting benefits and careers and the whole good." (Respondent 4)

This also corroborates other scholars' conclusions that structural infrastructure capability depends on formal organizational design, and that motivation and remuneration systems increase knowledge protection and loyalty (Pandey et al., 2018). Similarly, it has been argued that an organizational structure that espouses a consistent incentive scheme can support knowledge management initiatives (Gold et al., 2001; Nonaka \& Takeuchi, 1995). In addition, Brown and Duguid (2001); Grant (1996) and (Nonaka, 1994) also recommended that rewards, bonuses, incentives and an encouragement system are the best measures of structural capability.

Another theme identified from the interviewees' comments was the value of a flexible, horizontal Organizational style which facilitated an easy flow of information. The following quote describes meticulous system for sharing employees' innovative and creative ideas with their peers for approval, and rapidly adopting, protecting and implementing them and:

"We have spacious offices with open-door policy for our employees, pharmacists, and REDDs specialists so as to come up with an urgent formula that needs to get coded and sent to our headquarter for approval. Instantly, we code it, send it and once got approved our Labs manager put it into new product. Thus we innovate we have operationalized many innovative ideas through that ways" (Respondent 2)

This theme corroborates ideas put forward in other academic contributions. For instance, Armbrecht et al. (2001) define structural infrastructure as the physical design and organization, where appropriate physical structure, such as office design and locations, encourages the sharing and flow of knowledge. In the same vein, Gold et al. (2001) also stressed that flexible structures with flattened organizations, allow increased communication with employees and sharing behavior within the organization. Indeed, when an organization possesses good absorptive capacity, it has a superior motivation to invest in innovation because it has potential to succeed in the commercialization race. Hurmelinna-Laukkanen (2012) Thus, it can be confirmed that, in the case of this pharmaceutical MNE operating in Egypt, the organization's structure capability supports the protection of knowledge conversion for innovations by augmenting its absorptive capacity.

\subsection{Cultural Capability Supports Knowledge Sharing and Protection of Applications for Innovations}

Organizational culture as a concept in the knowledge management literature has been considered a significant element in effective knowledge management. The cultural constituent of infrastructure capability relates to the organization's philosophy and ideals, its outlook towards learning and the effect 
of culture on communication and interaction (Pandey et al., 2018). It encompasses the ability of an organization to motivate its teams to share long-lasting organizational valuable knowledge (Schneckenberg, Truong, \& Mazloomi, 2015). Knowledge application refers to operationalizing organizational knowledge to generate value, which can be mirrored in new products, and innovations (Mills \& Smith, 2011).

"We have an open-door policy for all employees and pharmacists who working either in the production lines or labs, once they have any ideas regarding innovations in a certain medicine, we adopt, analyze, and discuss the idea with our peers, labs, vice president, and CEOs, then if it fits, we operationalize it. We share knowledge in a very restricted, coded and confidential ways this is a part of our culture".( Respondent 1)

The respondents in the current research emphasized that the flexible and open-minded culture of their organization assists them in enriching their absorptive capacity in terms of acquiring, analyzing and converting this knowledge in a very protective manner into innovative medicines for their market dominance and competitive advantage. This corroborates the arguments of other scholars, for instance Lee and Choi (2003) who argue that an organizational culture where there is openness, cooperation, learning and trust can inspire the creation and exchange of knowledge. Moreover, it has been argued that a culture of openness and confidence is required to encourage the application and development of knowledge within an organization (Scarborough, Swan, \& Preston, 1999). Such a cultural environment encourages knowledge sharing and the utilization and application of knowledge into innovation (Ho, 2009).

"Our culture is to smile, welcome customers in a very friendly environment, care for each other; in turn we love and protect our company and ourselves simultaneously" (Respondent 3).

In the above excerpt, the senior managers emphasize that their friendly knowledge culture environment assists them to meet, collaborate, communicate and share know-how, monitoring, checking and protecting their physical buildings and assets, and, in turn, protecting their knowledge for utilization in innovative products. This is in line with many academic contributions, for instance, that of Mills and Smith (2011) who argues that a knowledge-friendly culture allows the firm to encourage knowledge ideals and shape a collaborative environment that facilitates knowledge sharing and knowledge creation among employees and its application in new outcomes and innovations.

Other respondents mentioned the endeavors made by their company to protect knowledge and the physical building by surveillance activities and means so as to prevent knowledge leakage and loss,

“... our weekly meetings with our security managers for analyzing the security measures in our company, cameras analysis, employees' movements, safety measures among employees. especially in the current pandemic period, experience, sharing our views and reviewing our internet security, firewalls, checking our monitoring systems, reviewing our labs files security, this is our culture etc.,"( Respondent 7)

This is in line with academic consensus: for instance, Desouza and Vanapalli (2005) argue that monitoring of workforces by tools of counterintelligence teams can be applied to proactively detect possible leaks and prevent possible damage to organizations.

In addition, knowledge-friendly organizational cultural rules, philosophies, beliefs and manners enhance effectiveness of knowledge management practices (Valaei, Rezaei, \& Emami, 2016). It appears that organizational culture and motivations are obligatory for effective application of knowledge management processes and activities into innovations (Iqbal, Latif, Marimon, Sahibzada, \& Hussain, 2019). Thus, the above theme emphasizes the role of cultural capability in boosting employees' absorptive capacity for supporting knowledge sharing and protecting application for innovations in the case of the pharmaceutical MNE operating in Egypt.

\subsection{Appropriability Regime Mechanisms for Protecting Knowledge and Innovation}

In investigating the influence of external and internal $(\mathrm{R} \& \mathrm{D})$ knowledge on innovation through the lens of absorptive capacity theory, it is essential to consider the flow of knowledge transition from potential to realized absorptive capacity. As illustrated in Figure 2, Zahra and George (2002) propose three constituents in their reconceptualization of absorptive capacity. namely activation triggers, social 
integration mechanisms and appropriability regimes. Since, chemical and pharmaceutical industries need to have strong appropriability regimes for their survival (Dodgson, Gann, \& Salter, 2008), the role of the appropriability regime is a focus of this research, as it has been conducted in a pharmaceutical organization where the appropriability regime is closely linked to innovation (Hurmelinna-Laukkanen, 2012). Indeed, the protection of knowledge is central to achieving and maintaining a competitive advantage and innovation (Liebeskind, 1996).

According to Hurmelinna-Laukkanen (2012) an appropriate regime for innovation and intangibles comprises institutional (formal), or more informal mechanisms. Appropriability mechanisms refer to mechanisms utilized by organizations to protect of knowledge and prevent it from being misused by others (Sofka \& Schmidt, 2004). Ahmad et al. (2014) identify four main knowledge protection areas: strategic-level management initiatives, operational-level knowledge protection processes, supporting technology infrastructure, and legal structures for knowledge protection. Secrecy patents, lead time, and other legal protection, are classified as constituents of appropriability (Cohen, Manion, \& Morrison, 2000) as reflected in the quotes below.

"We obtain information from our headquarter, suppliers, and raw materials producers located abroad where we have to sign a non-disclosure papers for acquiring new and unpublished materials and information like drug formulas, developed drugs, etc." (Respondent 1).

"Of course we have challenges in protecting and sharing our knowledge, for instance, when we are lacking the manufacturing lines to produce a certain medicine, we recourse to external associates who possess these capabilities to manufacture our innovative ideas and exploration but, they have to sign a non-disclosure forms not forever, just for at least five years, then they can manufacture their own medicine under their name and logo". (Respondent 2).

"We have concrete patent policy in order to protect our products, RED outcomes, and information. We also have a very restricted formal agreement with our allies, associates, collaborators and subsidiaries not to disclose our mutual information to externals and those who have no right to access to our knowledge" (Respondent 1).

All these senior managers of the pharmaceutical company emphasized the legal policies applied by their organization to prevent knowledge leaks and loss by compelling employees and external suppliers to sign non-disclosure agreements. Non-disclosure agreements are related to contract law, and legal structures for knowledge protection (Grossman, 2004; Olander, Hurmelinna-Laukkanen, \& Mahonen, 2009). Such agreements restrict "the use of information by prohibiting a contracting party from divulging data." Beyer (2001) and give organizations the right to sue the contracting party if this knowledge has been disclosed to a third party. That is aimed to control the use and disclosure of classified information by externals, which necessitates clarifying the meaning of what information is confidential, The research findings also concur with Olander, Hurmelinna-Laukkanen, and Heilmann (2011) who explain that NDAs are planned to encompass all types of confidential information, and normally comprise common guidelines regarding signees' commitments to protect confidential information in organization. The SMs emphasized that enforcing employees to sign NDAs will aid in protecting their innovative drugs, formulas, and innovations from being copied by third parties , Thus, the interviewee's comments confirmed their belief that the appropriability regime constitutes a key part in knowledge protection as it directly and positively determines innovation performance and incurs commercial gain (Hurmelinna-Laukkanen, 2012).

\subsection{The Role of Human Resource Management (HRM) in Protecting Knowledge for Innovation}

Protecting knowledge from leaks, loss and the risks incurred with these is always related to human resource management activities. However, this fact is often overlooked by academics and practitioners (Olander et al., 2011). Human resource management (HRM) is strongly linked to the role of intellectual property protection (Hurmelinna-Laukkanen \& Puumalainen, 2007) because the existence of a robust human resource management mechanism might inspire staff to interconnect more with their associates and partners. Thus, the human resource management mechanism and practices are closely linked to protection mechanisms and may have a positive influence on the organization's performance (Olander \& Hurmelinna-Laukkanen, 2010). This belief is strongly reflected in the descriptions and 
rationale given by the interviewees in the quotes below. They explain that their strategies for protecting their knowledge starts from the moment they recruiting their employees, when they train them using different HRM techniques to maintain confidentiality with their colleagues and associates and select with whom to discuss and what to discuss so as to shape their mindset for protecting their knowledge for innovations.

"Knowledge protection starts with our staff once they get recruited by giving induction period from two to six month on how they protect our knowledge, do not discuss even their salaries, daily routines, assigned tasks with their colleagues and externals. However, we give them some traditional tasks to see if they would continue with us mentally or not, how they approach ideas, and collected information" (Respondent 1)

"We have mutual training sessions, workshops, and seminars monthly with the compliance department so as to train our employees from different levels to comply with written agreements that they will not disclose our knowledge to third part', (Respondent 4).

This perception is in line with recommendations in the literature. For example, Olander et al. (2011) argue that the main human resource management practices concerning knowledge protection comprise choosing the right employees and appropriate instruction and preparation, particularly regarding their accountability towards knowledge protection and secrecy. Indeed, training is considering the superior element, owing to the accompanying modifications in organizational design, since it breaks down traditional departmental barriers and prevents knowledge from leaving an organization (Robbins, 2005).

In addition, the SMs also mentioned that they enforce their employees to a sign non-disclosure written agreement as a mean of legal protection of their knowledge. This is also corroborates the understanding in the literature for instance, by Olander and Hurmelinna-Laukkanen (2010) that "nondisclosure agreements can be utilized to keep employees within the firm or controlling their actions and communication." In the same vein, Hurmelinna-Laukkanen and Puumalainen (2007) argue that non-disclosure agreements and contracts used as HRM mechanisms are perceived as tools for preventing important employees from leaving one company and working for another and to control knowledge leakage and losses in organization.

Mir, Mir, and Mosca (2002) argue that productivity and job satisfaction stem from promoting organizational commitment and the wish to remain within the organization. The quote below illustrates that the managers interviewed also shared this view.

"We are making our staff to feel secure and safe in terms of their position, tenure, health insurance, bonuses, rewards, motivations, and instill the feeling that they are very important to us and constitute a huge value to our company, and transparency and clarity in our communications so as to be well prepared to protect our knowledge for their existence in our company, it is our culture" (Respondent 6)

The respondent's quote confirms the views of Liebeskind (1996) and Olander et al. (2011) that HRM schemes comprise salary rises, and employee perks, bonuses, motivations, and benefits and other mechanisms are beneficial for preventing knowledge from leaving the organization. Thus, it can be argued that the roles, activities and techniques of human resource management are indispensable for supporting the process of knowledge protection for innovation in organizations.

\subsection{Knowledge Hiding to Support Knowledge Protection for Innovation}

Knowledge acts as a strategic competitive component for organizations to enhance competitive advantage. However, although organizations have rooted strategies for knowledge sharing, it has been observed that most employees at some time abstain from knowledge-sharing practices in their organizations (Ruparel \& Choubisa, 2020). This phenomenon has been labeled as knowledge hiding by Connelly, Zweig, Webster, and Trougakos (2012) who define it as an "intentional attempt by an individual to withhold or conceal knowledge that has been requested by another person". According to Ruparel and Choubisa (2020) there are three ways in which individuals might hide demanded knowledge. The first way is rationalized hiding, where the knowledge holder gives a rational reason for not sharing the knowledge being asked for. The second is evasive hiding, where the knowledge holder 
gives misleading information or procrastinates when asked to share the required knowledge, and the third is playing dumb, where knowledge holder pretends ignorance of the requested knowledge.

Todorova and Durisin (2007) delineated absorptive capacity (AC) as "the organizational capabilities to recognize the value of new knowledge, to assimilate it, and to apply it to commercial ends (p. 774)." This is to illustrate absorptive capacity mediates relationship between knowledge hiding and knowledge protection (Bari, Abrar, Shaheen, Bashir, \& Fanchen, 2019). However; whether the relationship is beneficial or harmful for an organization has not been empirically explored previous to the current research. The interviewees' comments shed light on this question.

"Our knowledge is our innovations and creativity. Even in our monthly meetings with agents and colleagues from our headquarters, we cannot discuss our hub REDDs freely for fear that this knowledge leaks to cause damage of our efforts, however, we sometimes evade the discussion when it comes to our own subsidiary knowledge." (Respondent 1).

"In our meetings and seminars with our colleagues and our allies from the headquarters we cannot chat freely about our daily live in our company, tea-time is for tea talks not professional talks, we try to shift the discussion to different subject or just change the discussion subtly so as not to feel embarrassed" (Respondent 4).

"We cannot exchange our professional knowledge and information. But, if someone tried to ask for confidential information, I always confront him in an ethical way and say that I cannot declare such information because it is classified and privileged information and we cannot discuss that utterly, we keep our knowledge to protect our creativity, IPR and innovation" (Respondent 7).

These quotes from the interviewees corroborate scholarly contentions and empirical evidence that employees are sometimes deceptive (evasive hiding) by retaining significant facts about the information being asked for and rationalize knowledge hiding by giving justifications or postponing a discussion (Ruparel \& Choubisa, 2020). However, the core intention of the SMs in hiding knowledge is to maintain the security of their R\&D's knowledge and creative innovation. The interviewees believe that protecting their knowledge and hiding it from knowledge seekers, either by avoiding answering or confronting their requests or by providing reasons for the knowledge seeker that prevent them from declaring information, is the best way to preserve their organization's reputation, creativity and innovation. This is in line with Bari et al. (2019) claim that rationalized and evasive hiding does not significantly affect creativity and innovation. Furthermore, senior managers hide their knowledge in the pharmaceutical organization for the overall good of their organization and to promote innovation by keeping their knowledge privileged. This also concurs with the argument that such conduct does not essentially contain deception; it may have positive intents, to maintain confidentiality and respect the feelings of the third party and avoid consequences rather than to harm others Yang and Ribiere (2020) and Connelly et al. (2012). In the same vein, Xiao and Cooke (2019) argue that knowledge hiding is not always damaging, as it might be practiced to protect the organization or from self-interest. Furthermore, Courpasson and Younes (2018) posit that confidentiality could reinforce rather than damage organizations. Thus, knowledge hiding via absorptive capacity is not harmful or inhibiting to the relationship between knowledge seekers and requesters, nor can it damage trust among individuals and inhibit creativity and innovation as claimed by some authors (Fong, Men, Luo, \& Jia, 2018; Yang \& Ribiere, 2020). Thus, the findings of the current research, through the lens of the absorptive capacity theory, emphasise that knowledge hiding positively affects innovation and creativity and is a key component that assists the process used by the pharmaceutical MNE in Egypt to protect its knowledge to achieve innovation.

\subsection{Knowledge Management for Supporting Organizational Effectiveness for Innovation}

Organizational effectiveness has been defined by Daft (1995) as "the extent to which an organization achieves its objectives". Organizational effectiveness is the output of an organization and the way that it managed its knowledge deliberately within its structure and process capabilities (Gold et al., 2001):

"Currently we facing very fierce challenges in the pharmaceutical industry among both our counterparts and rivals because every company wants to dominate its products as effective against the (COVID-19) so 
pharmaceutical companies that vying for headhunting experts from Egypt and the overseas to get benefits of their know-how, but, due to our strategies of management of knowledge and its governance we excelled and dominated the market when the Egyptian Ministry of Health acknowledged two medicines of our products as essential in its standardized protocol for against (COVID-19). Thus we innovate and achieved competitive advantage and huge revenues". (Respondent 4).

"Based on our management of knowledge we have developed some German drug machine by enlarging its capacity to produce more than 20 ampules per minutes instead of 12 ampules. Thus we utilized our knowledge for innovation and save time and money". (Respondent 6)

"We innovate also by selling our Vita-Max plus to GlaxoSmithKline and reserve the same product, but we converted our knowledge and know-how to develop it, add more American components to it, put it a new package and information and produce it as more effective to achieve more revenues due to our innovations". (Respondent 1)

In the above excerpts, the senior managers gave examples of how the effectiveness of their organization was based on their strategies of protecting and managing their knowledge successfully, leading to high revenues, competitive position and innovation. This corroborates other academic contributions. For instance, Mahesh and Suresh (2009) suggest that contemporary organizations should govern the interchange of knowledge in order to preserve organizational effectiveness for superior performance. Similarly,, based on their empirical study, Zheng, Yang, and McLean (2010) conclude that "overall success, market share, profitability, growth rate, and innovativeness of the organization in comparison with key competitors" were the main measures for organizational effectiveness.

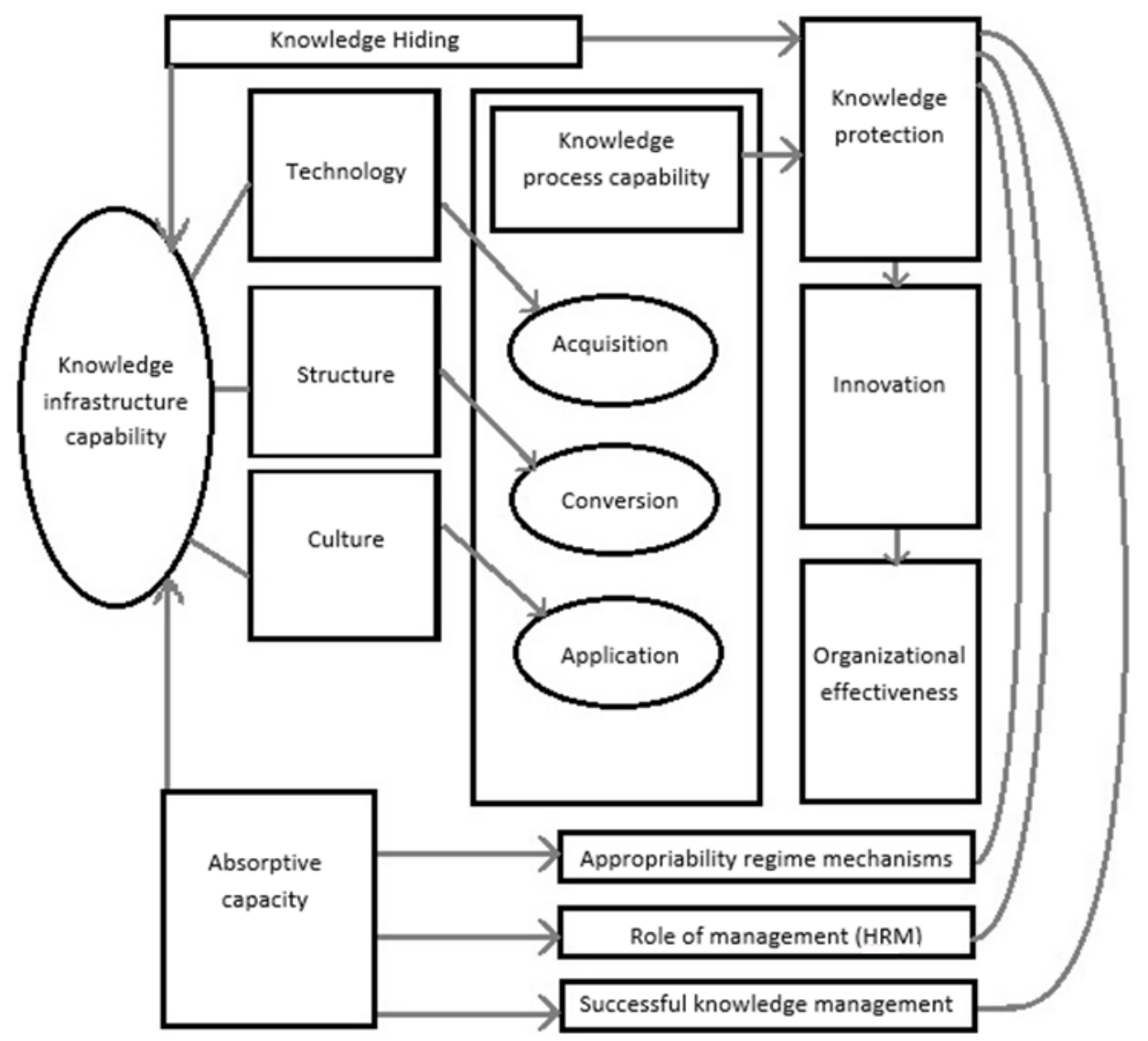

Figure-3.

Framework of strategies and supported mechanisms for innovation. 


\section{Conclusions}

Our framework Figure 3 illustrates the journey through the process and strategies that the pharmaceutical MNE use to acquire, assimilate, transform, apply and protect knowledge to achieve innovation, viewed through the lens of the absorptive capacity theory as a supportive mechanism for the knowledge management process. Prior research suggested that knowledge infrastructure capabilities (Kushwaha \& Rao, 2015) and integration of infrastructure and knowledge process capabilities (Pandey et al., 2018) leads to better performance. Our study demonstrates that successful knowledge management is more than this, it is that the knowledge infrastructure capabilities constitute the backbone of the knowledge process capabilities, supported by other constituents such as appropriability regime mechanisms, the role of management (HRM), knowledge management itself, and knowledge hiding. It has also been established that these capabilities are based on absorptive capacity via knowledge protection, aiming to achieve innovation and organizational effectiveness in terms of high revenues and commercial gains and enable knowledge protection for innovation. Knowledge hiding proved to be a new auxiliary for supporting the overall process for knowledge protection and innovation, despite the many claims of knowledge sharing and co-operative business as forms of competition. The role of management (HRM) was also found to be indispensable for training, selecting and nurturing employees' commitment and loyalty, thus protecting their knowledge, R\&D outcomes and innovation.

The outcomes gained from this research do not support the argument that knowledge infrastructure capabilities only can be the main cause of successful knowledge management, when accompanied by a knowledge management process (Gold et al., 2001). Rather, there are other constituents, as shown in Figure 3, which have to be in place in order to achieve innovation. From the above discussion, it can be concluded that organizational effectiveness in terms of commercial gain, performance in market share, a rise in revenues and innovation can be achieved through integrating all the constituents in Figure 3, which illustrates the final framework of strategies and supported mechanisms that assist the MNE pharmaceutical organization operating in Egypt to achieve innovation.

\subsection{Suggestions for Future Research}

Future studies are required to continue the present research posing different research questions. The current research applied a qualitative approach to address the research questions at the senior management level; further studies are suggested to investigate the role of different strategic positions such as middle managers, team level or frontline managers and to study those who can act in achieving organizational effectiveness in different contexts or industries. Future studies are suggested to apply the hypothetical framework and conceptual model to larger groups of target respondents (sample), to explore whether studies of other organizations produce similar results. Moreover, future research is required to employ different research instruments in more vibrant industries, since dynamic environments necessitate superior absorptive capacity of organizations to enable innovation. Furthermore, the specific influence of organizational culture and structure as different dimensions in achieving organizational effectiveness and innovation could be investigated. The current research makes a contribution to managerial practices with an indication of how integrating knowledge infrastructure capability as backbone for knowledge process capability can bring success to knowledge management in organization. The role of HRM can also be promoted and invigorated to instill loyalty and commitment to maintain confidentiality of knowledge for achieving innovation in organizations.

\subsection{Limitations}

Limitations of the current research are in terms of its qualitative research approach, where the researchers' perceptions raise questions of generalizability, regarding the degree to which the research results could be applied to different types of organizations. Since the research aim was to investigate the use of absorptive capacity theory as lens for supporting the process of knowledge management in organization, additional research is required to ratify the validity of the concepts utilized when applied 
through quantitative inquiry. Furthermore, due to the knowledge- and research-intensive nature of the case organization, as a pharmaceutical MNE, requests for different managerial levels were refused because of issues of confidentiality that restricted the research sample to SMs only. Nevertheless, it is believed that in the current research, keeping to a standard interview protocol may have significantly reduced this limitation (Yin, 1994).

\section{References}

Abualoush, S., Masa'deh, R., Bataineh, K., \& Alrowwad, A. (2018). The role of knowledge management process and intellectual capital as intermediary variables between knowledge management infrastructure and organization performance. Interdisciplinary Journal of Information, Knowledge, and Management, 13, 279-309. Available at: https://doi.org/10.28945/4088.

Ahmad, A., Bosua, R., \& Scheepers, R. (2014). Protecting organizational competitive advantage: A knowledge leakage perspective. Computers $\mathcal{E}^{2}$ Security, 42, 27-39. Available at: https://doi.org/10.1016/j.cose.2014.01.001.

Alavi, M., \& Leidner, D. E. (2001). Knowledge management and knowledge management systems: Conceptual foundations and research issues. MIS Quarterly, 25(1), 107-136. Available at: https://doi.org/10.2307/3250961.

Albort-Morant, G., Henseler, J., Cepeda-Carrión, G., \& Leal-Rodríguez, A. L. (2018). Potential and realized absorptive capacity as complementary drivers of green product and process innovation performance. Sustainability, 10(2), $381-401$. Available at: https://doi.org/10.3390/su 10020381.

Annansingh, F. (2005). Exploring the risks of knowledge leakage: An information systems case study approach. InTech Open Science, Open Minds, Croatia. Retrieved from: http://cdn.intechopen.com/pdfs ᄀwm/33417.pdf.

Appleyard, M. M. (1996). How does knowledge flow? Interfirm patterns in the semiconductor industry. Strategic Management Journal, 17(S2), 137-154. Available at: https://doi.org/10.1002/smj.4250171112.

Arias-Pérez, J., Lozada, N., \& Henao-García, E. (2020). When it comes to the impact of absorptive capacity on co-innovation, how really harmful is knowledge leakage? Journal of Knowledge Management, 24(8), 1841-1857. Available at: https://doi.org/10.1108/jkm-02-2020-0084.

Armbrecht, F., Chapas, R., Chappelow, C., Farris, G., Friga, P., Hartz, C., \& Whitwell, G. (2001). Knowledge management in research and development. Knowledge Management in Research and Development, 44(4), 28-48. Available at: https://doi.org/10.1080/08956308.2001.11671438.

Barão, A., de Vasconcelos, J. B., Rocha, Á., \& Pereira, R. (2017). A knowledge management approach to capture organizational learning networks. International Journal of Information Management, 37(6), 735-740. Available at: https://doi.org/10.1016/j.ijinfomgt.2017.07.013.

Bari, M. W., Abrar, M., Shaheen, S., Bashir, M., \& Fanchen, M. (2019). Knowledge hiding behaviors and team creativity: The contingent role of perceived mastery motivational climate. Sage Open, 9(3), 2158244019876297. Available at: https://doi.org/10.1177/2158244019876297.

Barley, W. C., Treem, J. W., \& Kuhn, T. (2018). Valuing multiple trajectories of knowledge: A critical review and agenda for knowledge management research. Academy of Management Annals, 12(1), 278-317. Available at: https://doi.org/10.5465/annals.2016.0041.

Barney, J. (1991). Firm resources and sustained competitive advantage. Journal of Management, 17(1), 99-120. Available at: https://doi.org/10.1177/014920639101700108.

Basit, T. (2003). Manual or electronic? The role of coding in qualitative data analysis. Educational Research, 45(2), $143-154$. Available at: https://doi.org/10.1080/0013188032000133548.

Beyer, G. W. (2001). Modern dictionary for the legal profession (3rd ed.). Buffalo, NY: William S. Hein \& Co., Inc.

Boisot, M. (1999). Knowledge assets. New York: Oxford University Press.

Boyatzis, R. E. (1998). Transforming qualitative information: Thematic analysis and code development. Thousand Oaks, CA: Sage.

Braun, V., \& Clarke, V. (2006). Using thematic analysis in psychology. Qualitative Research in Psychology, 3, 77-101. Available at: https://doi.org/10.1191/1478088706qp063oa.

Brown, J. S., \& Duguid, P. (2001). Structure and spontaneity: Knowledge and organization. In Nonaka, I., \& Teece, D. (Eds.), Managing Industrial Knowledge: Creation, Transfer and Utilization (pp. 44-67). London: Sage Publications.

Cappellari, G., Welter, C. V., Hermes, L. C., \& Sausen, J. O. (2019). Absorptive capacity: Components and organizational mechanisms for its development. RAM. Mackenzie Administration Magazine, 20(6). Available at: https://doi.org/10.1590/1678-6971/eRAMD190028.

Cassol, A., Gonçalo, C. R., \& Ruas, R. L. (2016). Redefining the relationship between intellectual capital and innovation: The mediating role of absorptive capacity. BAR-Brazilian Administration Review, 13(4), 1-25. Available at: https://doi.org/10.1590/1807-7692bar2016150067.

Chakravarthy, B., McEvily, S., Doz, Y., \& Rau, D. (2005). Knowledge management and competitive advantage. In M. EasterbySmith \& M. A. Lyles (Eds.), Handbook of organizational learning and knowledge management (pp. 104-121). Oxford: Blackwell Publishing.

Journal of Contemporary Research in Business, Economics and Finance
ISSN: $2641-0265$
Vol. 3, No. 3, pp. $109-127,2021$
DOI: $10.33094 / 26410265.2021 .33 .109 .127$
C) 2021 by the authors; licensee Learning Gate


Chiu, C.-N., \& Chen, H.-H. (2016). The study of knowledge management capability and organizational effectiveness in Taiwanese public utility: The mediator role of organizational commitment. Springer Plus, 5(1), 1-34. Available at: https://doi.org/10.1186/s40064-016-3173-6.

Cohen, L., Manion, L., \& Morrison, K. (2000). Research methods in education (5th ed.). London: Routledge Falmer.

Cohen, W. M., \& Levinthal, D. A. (1990). Absorptive capacity: A new perspective on learning and innovation. Administrative Science Quarterly, 35(1), 128-152. Available at: https://doi.org/10.2307/2393553.

Connelly, C. E., Zweig, D., Webster, J., \& Trougakos, J. P. (2012). Knowledge hiding in organizations. Journal of Organizational Behavior, 33(1), 64-88. Available at: https://doi.org/10.1002/job.737.

Courpasson, D., \& Younes, D. (2018). Double or Quits: Understanding the links between secrecy and creativity in a project development process. Organization Studies, 39(2/3), 271-295. Available at: https://doi.org/10.1177/0170840617727780.

Daft, R. L. (1995). Organizational theory and design. Chula Vista, CA: South-Western College Publications.

Davenport, T. H., \& Prusak, L. (1998). Working knowledge: How organizations manage what they know. Boston: Harvard Business School Press.

Desouza, K. C., \& Vanapalli, G. K. (2005). Securing knowledge in organizations: Lessons from the defense and intelligence sectors. International Journal of Information Management, 25(1), 85-98. Available at: https://doi.org/10.1016/j.ijinfomgt.2004.10.007.

Dodgson, M., Gann, D., \& Salter, A. (2008). The management of technological innovation: Strategy and practice. Oxford; New York: Oxford University Press.

Fong, S. W., Men, C., Luo, J., \& Jia, R. (2018). Knowledge hiding and team creativity: The contingent role of task interdependence. Management Decision, 56(2), 329-343. Available at: https://doi.org/10.1108/md-1 1-2016-0778.

Gold, A. H., Malhotra, A., \& Segars, A. H. (2001). Knowledge management: An organizational capabilities perspective. Journal of Management Information Systems, 18(1), 185-2 14. Available at: https://doi.org/10.1080/0742 1222.2001.11045669.

Grant, R. M. (1996). Toward a knowledge-based theory of the firm. Strategic Management Journal, 17(S2), 109-122. Available at: https://doi.org/10.1002/smj.4250171110.

Grossman, M. E. (2004). Technology law: What every business (and Business-Minded Person) needs to know. Lanham, MD: The Scarecrow Press, Inc.

Hernandez, E., Sanders, W. G., \& Tuschke, A. (2015). Network defense: pruning, grafting, and closing to prevent leakage of strategic knowledge to rivals. Academy of Management Journal, 58(7), 1233-1260. Available at: https://doi.org/10.5465/amj.2012.0773.

Ho, C. (2009). The relationship between knowledge management enablers and performance. Industrial Management \& Data Systems, 109(1), 98-1 17. Available at: https://doi.org/10.1108/02635570910926618.

Holsapple, C. W., \& Joshi, K. D. (2001). Organizational knowledge resources. Decision Support Systems, 31(1), 39-54.

Hurmelinna-Laukkanen, P. (2012). Constituents and outcomes of absorptive capacity-appropriability regime changing the game. Management Decision, 5o(7), 1178-1199. Available at: https://doi.org/10.1108/00251741211246950.

Hurmelinna-Laukkanen, P., \& Puumalainen, K. (2007). Nature and dynamics of appropriability: Strategies for appropriating returns on innovation. $R \Theta^{2} d$ Management, 37(2), 95-112. Available at: https://doi.org/10.1111/j.14679310.2007.00460.x.

Inkpen, A. C., \& Beamish, P. W. (1997). Knowledge, bargaining power, and the instability of international joint ventures. Academy of Management Review, 22(1), 177-202. Available at: https://doi.org/10.2307/259228.

Iqbal, A., Latif, F., Marimon, F., Sahibzada, U. F., \& Hussain, S. (2019). From knowledge management to organizational performance: Modelling the mediating role of innovation and intellectual capital in higher education. Journal of Enterprise Information Management, 32(1), 36-59. Available at: https://doi.org/10.1108/jeim-04-2018-0083.

Jennex, M. E., \& Durcikova, A. (2013). Assessing knowledge loss risk. Paper presented at the 2013 46th Hawaii International Conference on System Sciences (HICSS) in Honolulu, HI, 3478-3487.

Khamseh, H. M., \& Jolly, D. (2008). Knowledge transfer in alliances: Determinant factors. Journal of Knowledge Management, 12(1), 37-50. Available at: https://doi.org/10.1108/13673270810852377.

Kushwaha, P., \& Rao, M. (2015). Integrative role of KM infrastructure and KM strategy to enhance individual competence. VINE, 45(3), 376-396. Available at: https://doi.org/10.1108/vine-02-2014-0014.

Lee, S., Kim, B. G., \& Kim, H. (2012). An integrated view of knowledge management for performance. Journal of Knowledge Management, 16(2), 183-203. Available at: https://doi.org/10.1108/13673271211218807.

Lee, S.-C., Chang, S.-N., Liu, C.-Y., \& Yang, J. (2007). The effect of knowledge protection, knowledge ambiguity, and relational capital on alliance performance. Knowledge and Process Management, 14(1), 58-69. Available at: https://doi.org/10.1002/kpm.270.

Lee, H., \& Choi, B. (2003). Knowledge management enablers, processes, and organizational performance: An integrative view and empirical examination. Journal of Management Information Systems, 20(1), 179-228. Available at: https://doi.org/10.1080/07421222.2003.11045756.

Leech, B. L. (2002). Asking questions: Techniques for semistructured interviews. PS: Political Science E゚ Politics, 35(4), 665-668. Available at: https://doi.org/10.1017/s 1049096502001129.

Lewins, A., \& Silver, C. (2007). Using software in qualitative research: A step-by-step guide. London: Sage.

Journal of Contemporary Research in Business, Economics and Finance
ISSN: 2641-O265
Vol. 3, No. 3, pp. $109-127,2021$
DOI: $10.33094 / 26410265.2021 .33 .109 .127$
C 2021 by the authors; licensee Learning Gate


Liebeskind, J. P. (1996). Knowledge, strategy, and the theory of the firm. Strategic Management Journal, 17(S2), 93-107. Available at: https://doi.org/10.1002/smj.4250171109.

Lin, H.-F. (2007). Effects of extrinsic and intrinsic motivation on employee knowledge sharing intentions. Journal of Information Science, 33(2), 135-149. Available at: https://doi.org/10.1177/0165551506068174.

Mahesh, K., \& Suresh, J. (2009). Knowledge criteria for organization design. Journal of Knowledge Management, 13(4), 41-51. Available at: https://doi.org/10.1108/13673270910971815.

Manhart, M., \& Thalmann, S. (2015). Protecting organizational knowledge: A structured literature review. Journal of Knowledge Management, 19(2), 190-211. Available at: https://doi.org/10.1108/jkm-05-2014-0198.

Marti, J. M. V. (2000). ICBS: Intellectual capital benchmarking systems. International Journal of Technology Management, 20(5-8), 799-818. Available at: https://doi.org/10.1504/ijtm.2000.002890.

Mikhailov, A., \& Reichert, F. M. (2019). Influence of absorptive capacity on innovation: A systematic literature review. RAM. Mackenzie Administration Magazine, 20(6), 1-27. Available at: https://doi.org/10.1590/1678-6971/eramd 190033.

Mills, A. M., \& Smith, T. A. (2011). Knowledge management and organizational performance: A decomposed view. Journal of Knowledge Management, 15(1), 156-171. Available at: https://doi.org/10.1108/13673271111108756.

Mir, A., Mir, R., \& Mosca, J. B. (2002). The new age employee: An exploration of changing employee organization relations. Public Personnel Management, 31(2), 187-200. Available at: https://doi.org/10.1177/009102600203100205.

Nodari, F., Oliveira, M., \& Maçada, A. C. G. (2016). Organizational performance through the donation and collection of interorganizational knowledge. VINE Journal of Information and Knowledge Management Systems, 46(1), 85-103. Available at: https://doi.org/10.1108/vjikms-08-2014-0052.

Nonaka, I., \& Takeuchi, H. (1995). The knowledge-creating company: How Japanese companies create the dynamics of innovation? New York: Oxford University Press.

Nonaka, I. (1994). A dynamic theory of organizational knowledge creation. Organization Science, 5(1), 14-37. Available at: https://doi.org/10.1287/orsc.5.1.14.

Olander, H., Hurmelinna-Laukkanen, P., \& Mahonen, J. (2009). What's small size got to do with it - protection of intellectual assets in SMEs. International Journal of Innovation Management, 13(3), 349-370. Available at: https://doi.org/10.1142/s1363919609002339.

Olander, H., Hurmelinna-Laukkanen, P., \& Heilmann, P. (2011). Do SMEs benefit from HRM-related knowledge protection in innovation management? International Journal of Innovation Management, 15(03), 593-616. Available at: https://doi.org/10.1142/s1363919611003453.

Olander, H., \& Hurmelinna-Laukkanen, P. (2010). The effects of HRM-related mechanisms on communication in R\&D collaboration. International Journal of Innovation Management, 14(03), 415-433. Available at: https://doi.org/10.1142/s1363919610002714.

Pandey, S. C., \& Dutta, A. (2013). Role of knowledge infrastructure capabilities in knowledge management. Journal of Knowledge Management, 17(3), 435-453. Available at: https://doi.org/10.1108/jkm-1 1-2012-0365.

Pandey, S. C., Dutta, A., \& Nayak, A. K. (2018). Organizational capabilities and knowledge management success: A quartet of case studies. Kybernetes, 47(1), 222-238. Available at: https://doi.org/10.1108/k-01-2017-0041.

Pentland, B. T. (1995). Information systems and organizational learning: The social epistemology of organizational knowledge systems. Accounting, Management and Information Technologies, 5(1), 1-21. Available at: https://doi.org/10.1016/09598022(95)90011-x.

Robbins, S. P. (2005). Essentials of organizational behavior (8th ed.). NJ: Pearson Prentice Hall.

Ruggles, R. (1998). The state of the notion: Knowledge management in practice. California Management Review, 40(3), 80-89. Available at: https://doi.org/10.2307/41165944.

Ruparel, N., \& Choubisa, R. (2020). Knowledge hiding in organizations: A retrospective narrative review and the way forward. Dynamic Relationships Management Journal, 9(1), 5-22.

Scarborough, H., Swan, J., \& Preston, J. (1999). Knowledge management: A literature review. London: Institute of Personnel and Development.

Schneckenberg, D., Truong, Y., \& Mazloomi, H. (2015). Microfoundations of innovative capabilities: The leverage of collaborative technologies on organizational learning and knowledge management in a multinational corporation. Technological Forecasting and Social Change, 100, 356-368. Available at: https://doi.org/10.1016/j.techfore.2015.08.008.

Smith, J. A., Larkin, M., \& Flowers, P. (2009). Interpretative phenomenological analysis: Theory, method and research. London, UK: Sage.

Sofka, W., \& Schmidt, T. (2004). I like the way you move: An emperical investigation into the mechanisms behind first mover and follower strategies. ZEW Discussion Papers, (No. 04-87).

Todorova, G., \& Durisin, B. (2007). Absorptive capacity: Valuing a reconceptualization. Academy of Management Revierw, 32(3), 774-786. Available at: https://doi.org/10.5465/amr.2007.25275513.

Townley, C. T. (2003). Will the academy learn to manage knowledge? Knowledge management can improve academic effectiveness and accountability-if campuses can overcome their constraints. Educause quarterly, 26(2), 8-11.

Valaei, N., Rezaei, S., \& Emami, M. (2016). Impact of exploitative learning strategy on Malaysian SMEs' creativity and innovation capabilities. International Journal of Management and Enterprise Development, 15(4), 328-354. Available at: https://doi.org/10.1504/ijmed.2016.10000580. 
Venkitachalam, K., \& Willmott, H. (2015). Factors shaping organizational dynamics in strategic knowledge management. Knowledge Management Research E Practice, 13(3), 344-359. Available at: https://doi.org/10.1057/kmrp.2013.54.

Wu, L., \& Chen, J.-L. (2014). Knowledge management driven firm performance: The roles of business process capabilities and organizational learning. Journal of Knowledge Management, 18(6), 1141-1164. Available at: https://doi.org/10.1108/jkm-05-2014-0192.

Xiao, M., \& Cooke, F. L. (2019). Why and when knowledge hiding in the workplace is harmful: a review of the literature and directions for future research in the Chinese context. Asia Pacific Journal of Human Resources, 57(4), 470-502. Available at: https://doi.org/10.1111/1744-7941.12198.

Yang, K., \& Ribiere, V. (2020). Drivers of knowledge hiding in the university context. Online Journal of Applied Knowledge Management, 8(1), 99-116. Available at: https://doi.org/10.36965/ojakm.2020.8(1)99-116.

Yin, R. K. (1994). Case study research: Design and methods. Beverly Hills, CA: Sage Publications.

Zahra, S. A., \& George, G. (2002). Absorptive capacity: A review, reconceptualization, and extension. Academy of Management Review, 27(2), 185-203. Available at: https://doi.org/10.5465/amr.2002.6587995.

Zheng, W., Yang, B., \& McLean, G. N. (2010). Linking organizational culture, structure, strategy, and organizational effectiveness: Mediating role of knowledge management. Journal of Business Research, 63(7), 763-771. Available at: https://doi.org/10.1016/j.jbusres.2009.06.005. 